\title{
RESIDENTIAL CHRONOLOGY, HOUSEHOLD SUBSISTENCE, AND THE EMERGENCE OF SOCIOECONOMIC TERRITORIES IN LEEWARD KOHALA, HAWAI'I ISLAND
}

\author{
Julie S Field ${ }^{1}$ Thegn N Ladefoged ${ }^{2} \bullet$ Warren D Sharp $^{3} \bullet$ Patrick V Kirch $^{4}$
}

\begin{abstract}
Previous research in leeward Kohala, Hawai'i Island, has determined that the Leeward Kohala Field System (LKFS), a vast agricultural zone covering $\sim 60 \mathrm{~km}^{2}$, developed between the 14th and 18th centuries AD. Additional analyses have documented the establishment of traditional socioeconomic territories, known as ahupua ' $a$, in tandem with the expansion of the field system. This article further refines the chronology of human settlement and socioeconomic development in leeward Kohala through the analysis of deposits associated with prehistoric residences. Based upon survey and excavation, we present a chronology for Hawaiian household transition and economic development in 2 study areas of leeward Kohala, spanning the field system to the coast. Forty-nine radiocarbon dates from short-lived plant materials and $5{ }^{230} \mathrm{Th}$ dates on corals from residential and ritual features are synthesized into 3 temporal periods, which allow for comparison of residential size, distribution, number, and associated faunal materials from archaeological deposits. Changes in household composition and economy are suggested to have developed in tandem with the establishment of individual ahupua ' $a$ and land divisions within them, and the further development of agricultural production.
\end{abstract}

\section{INTRODUCTION}

The Hawai'i Biocomplexity Project is a collaboration among archaeologists, ecologists, demographers, and others who seek to understand the long-term dynamic relationships that linked prehistoric Hawaiian populations with the agroecosystems of Kohala, Hawai' ${ }^{1}$ Island (Vitousek et al. 2004; Lee et al. 2006; Ladefoged et al. 2008; Kirch 2011). The investigation of residential patterning and chronology has been a key topic within this research project, as it provides a direct measure of human population dynamics in response to agricultural investment, environmental change, and socioeconomic transformations. Precontact residential features in the district of Kohala, located on the northern tip of the island of Hawai $i$, were first investigated archaeologically in the late 1960s and early 1970s (Pearson 1968; Soehren 1969; Rosendahl 1972; Tuggle and Griffin 1973). Following the research questions of the time, investigation of residential features focused primarily on chronology, and on the determination of the spatial and temporal relationships between coastal residences and agricultural features in the uplands. The theoretical basis for this approach meshed the ideas of adaptive change and ecological systems with anthropological models of Hawaiian society, settlement patterns, and subsistence systems (Newman 1969, 1970). Forty years later, we have returned to the issue of residential features and subsistence systems in Kohala, oriented by a similar theoretical perspective, that of human ecodynamics (McGlade 1995; Barton et al. 2004).

Re-examination of archaeological residences in the Kohala case is particularly pressing, as much of the research completed in the 1960s-70s employed hydration-rind dating of volcanic glass, which has subsequently been shown to be unreliable (Graves and Ladefoged 1994; Tuggle and Spriggs 2000). Further, investigation of agricultural features in both windward and leeward Kohala has employed more rigorous sampling requirements for radiocarbon dating (Ladefoged and Graves $2000,2006,2008$ ), and the resulting chronology for these features has, until recently (Ladefoged and Graves 2008; Field al. 2010b), been only minimally associated with evidence for human residence.

\footnotetext{
${ }^{1}$ Department of Anthropology, The Ohio State University, 4034 Smith Laboratory, 174 W. 18th Avenue, Columbus, Ohio 43210, USA. Email: field.59@osu.edu.

2 Department of Anthropology, Private Bag 92019, The University of Auckland, Auckland, New Zealand.

${ }^{3}$ Berkeley Geochronology Center, 2455 Ridge Rd., Berkeley, California 94709, USA.

${ }^{4}$ Departments of Anthropology and Integrative Biology, The University of California, Berkeley, 232 Kroeber Hall, Berkeley, California 94720, USA.
} 
This paper presents a series of $49{ }^{14} \mathrm{C}$ and $5{ }^{230} \mathrm{Th}$ dates for deposits associated with residential and ritual features in leeward Kohala. This data set is the result of extensive survey and excavation in leeward Kohala carried out between 2007 and 2009, generated from 2 study areas that span the ahupua 'a of Makeanehu, Kaiholena, Kālala, Makiloa, and Pahinahina (Figure 1). In traditional Hawaiian society, ahириа ' $a$ were territorial units administered by a chief and his land manager, and occupied by a community that was in theory economically self-sufficient. In leeward Kohala, these ahupua ' $a$ ran from the coast to the mountain ridge, thus cross-cutting the island's main ecological zones. All of the dated sample materials are derived from short-lived plant taxa and from archaeological contexts associated with residential architecture. We evaluate these dates and contexts to construct a synthetic chronology for occupation, residence establishment, and settlement patterns in leeward Kohala. This chronology can be linked to current models of agricultural production and population growth that have been developed for the Leeward Kohala Field System (LKFS) (Ladefoged et al. 1996, 2003, 2005; Ladefoged and Graves 2000, 2006, 2008), an expanse of agricultural features that extend across a large portion of the upland area of leeward Kohala. As a comparison, we also examine subsistence trends at the household level via the analysis of marine faunal remains (marine mollusks and echinoderms) and bones of introduced domesticates (dog and pig), which were harvested or raised for food. From these results, we argue that the history of human residences on the coast and in the field system traces temporal patterns that were determined by population growth, the emergence of the ahириа ' $a$ as an integrated socioeconomic unit, and the influence of elites in society. Our analysis also has implications for broader demographic trends and social trajectories in Hawaiian prehistory.

\section{Previous Investigations of Residential Features in Leeward Kohala}

Interest in the spatiotemporal dynamics of settlement patterns in Kohala began with the Lapakahi archaeological program of the 1960s and 1970s, which sought to investigate the chronology and spatial patterning of prehistoric Hawaiian cultural adaptations to the Hawaiian ecosystem (Newman 1969, 1970; Pearson 1968; Tuggle and Griffin 1973). The principal site investigated was Koaie, a coastal village that had been noted during missionary William Ellis' 1823 tour of Hawai'i Island (Ellis 1825:408). Survey and excavation methodologies at Lapakahi were also influenced by the settlement pattern approach of Green in Makaha Valley, O`ahu (Green 1969, 1970), which emphasized the spatial relationships between residential, agricultural, and ritual features. In following years, the research program at Lapakahi expanded beyond Koaie into the surrounding coastline and uplands, documenting the location and morphology of surface architecture within a large portion of the Lapakahi ahupua 'a (Soehren 1969; Rosendahl 1972, 1994). Additional studies of the southern coast of Kohala were completed as part of a survey for the State of Hawai'i (Bonk 1968).

Rosendahl's $(1972,1994)$ study of settlement patterns in the uplands of Lapakahi sought to define and identify residential architecture within the LKFS, and also to explore the temporal relations between architectural types and residences along the coast and uplands. His research employed analyses of residential feature clustering, proximity analysis of trails, and agricultural features to identify possible social units. The excavation of complexes of C-shaped and L-shaped residential structures as well as raised stone and earthen platforms and rectangular structures allowed Rosendahl to produce chronologies (based on volcanic glass dates and ${ }^{14} \mathrm{C}$ dating of unidentified charcoal) that indicated the occupation of the region as early as the 14th century AD. Moreover, the agricultural system of field alignments, trails, and temporary and permanent shelters was thought to be connected to the coastal Lapakahi fishing communities via a network of trails. Rosendahl also suggested that episodes of residence construction, abandonment, and modification were indicative of seasonal mobility by dryland farmers in the field system, although in later centuries permanent occupations became more common, and the ahupua 'a population appeared to have transitioned into a network of permanent, but dispersed, settlements (Rosendahl 1994:64). 

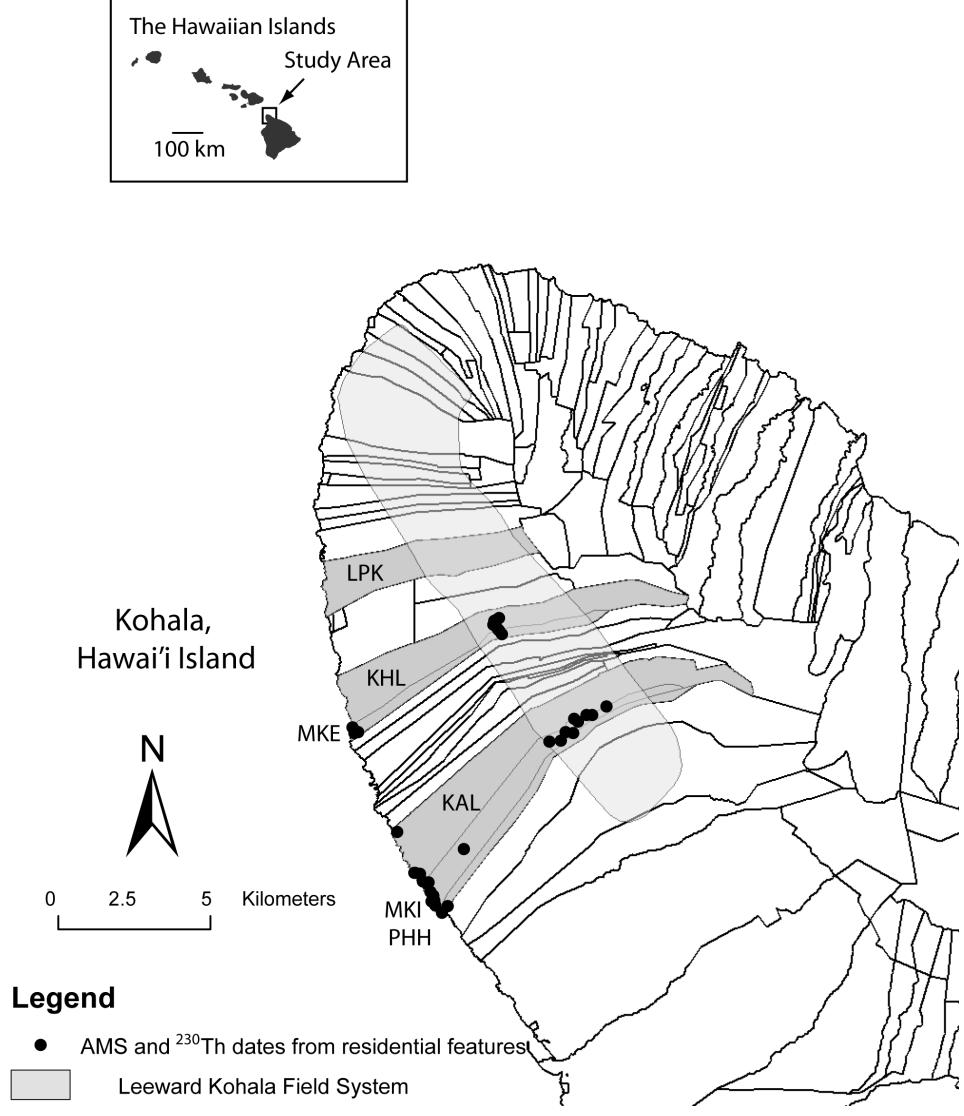

Figure 1 Map of Kohala, Hawai' 'i, showing the location of ahupua ' $a$ mentioned in text (LPK, Lapakahi, KHL, Kaiholena, MKE, Makeanehu, KAL, Kālala, MKI, Makiloa, and PHH, Pahinahina). The extent of the Leeward Kohala Field System is shown in light gray, and the location of the $54 \mathrm{AMS}$ and ${ }^{230} \mathrm{Th}$ dates from deposits associated with residential features are indicated by the black circles.

In the 1980s and 1990s, cultural resource management projects associated with land development and road construction investigated a range of residential features along the coastline of leeward Kohala. Studies by Schilt and Sinoto (1980), Burgett and Rosendahl (1993), Dunn and Rosendahl (1989), Kaschko (1982), and Wulzen and Goodfellow (1995) identified complexes of C-shaped shelters, platforms, enclosures, and terraces along the coastlines of Kapaanui, Puakea, and Mahukona ahириа ' $a$, located near the northern tip of Kohala. Dates from deposits associated with these features were based upon ${ }^{14} \mathrm{C}$ dating of unidentified charcoal and hydration-rind dating of volcanic glass and suggest ages between AD 1400-1600, although the volcanic glass hydration dates are now thought to be unreliable. Further to the south, unidentified charcoal dates from residential features on the coasts of Kahua and Waika ahupua 'a (O'Hare and Goodfellow 1995; Graves and Franklin 1998) have also provided dates within the range of AD 1400-1750. All of these dates came from deposits within features that were small enclosures, mounds, and platforms, probably used as either temporary or permanent residences.

Only a generalized model of prehistoric residence in Kohala can be constructed as a result of these prior research programs. In terms of chronology, the region appears to have been occupied between 
AD 1400 and the contact period (late 1700s), and an increase in the number of residences over this time is generally assumed. Subsistence activities along the coast and within the field system are assumed to have been independent in prehistory, but limited analyses have not allowed for a full examination of the economics of particular ahupua ' $a$. In sum, understanding of prehistoric settlement in Leeward Kohala is fragmentary, and major questions pertaining to population size, household size and composition, settlement patterning, modes of subsistence, and chronology have yet to be fully addressed or answered.

\section{METHODS: INVESTIGATION OF RESIDENTIAL FEATURES WITHIN LEEWARD AHUPUA'A}

Our recent research examines the chronology and spatial patterning of archaeological deposits and associated residential features in the uplands and coastal regions of 5 ahириа ' $a$ in leeward Kohala, namely Pahinahina, Makiloa, Kālala, Makeanehu, and Kaiholena (Figure 1). The first stage of our research consisted of an intensive survey of the coastal and upland regions. Using close walking transects and Trimble GeoXH GPS instruments, 748 archaeological features were recorded and issued unique alphanumeric identifiers. In the coastal sections, the survey recorded visible surface architecture between the coastline and $540 \mathrm{~m}$ inland. In the uplands, the survey extended from the lower elevation limits of the LKFS to the higher elevations, portions of which had been disturbed by historic bulldozing.

The morphological and functional classifications used to define these features are outlined in detail in Field et al. (2010b:58-60), and are summarized briefly here. Surface architecture of leeward Kohala varies greatly in morphology, the most common consisting of stacked-stone open enclosures or shelters ("C", "J", and "U" shaped), rectangular enclosures, and terraces. Oftentimes, an enclosure would be associated with a secondary feature by contiguous abutment. We defined each surface feature as a component, and in cases of multiple contiguous surface features we described the combined structure as a "multicomponent" feature, which may have been partially constructed over time, or reconstructed later in time with particular components added or removed. Other surface features recorded in the survey included single alignments of stacked stone, mounds, modified outcrops, midden scatters, platforms of stacked stone, terraces of earth with stone facing, and enclosures with a robust windward wall and a terrace front.

We identified residential activities associated with surface architecture based upon the presence of faunal remains (especially shellfish) and/or lithic debitage in the surface deposits. The presence of an enclosing wall, raised stone terrace, pavements, or platforms are also designated as related to residence. Although it was not possible to determine the association of cultural deposits and surface architecture without excavation, larger-sized (in terms of interior surface area and wall height) enclosures and terraces that also were associated with dense surface faunal remains were termed "primary residences," while smaller structures with sparser midden were designated as "secondary residences." The definition of primary and secondary residences allows for further analysis of feature function and spatial patterning, as we assume that primary residences were the main focus of habitation (e.g. sleeping and household activities). Secondary residential features were perhaps associated with specific activities such as ritual use, craft production, cooking, or storage, and were used on a daily basis or intermittently throughout the year (such as agricultural field shelters). We also identified several structures that were likely heiau (ritual structures) within our study areas. Constructed with large basal stones and massive walls that extended to several meters in height, these sites were used for community-level rituals and were sites of tribute collection. Two of these features (KAL-1 and PHH-13) located on the coast were investigated with test excavations in order to obtain samples for dating. A total of 320 residential features and heiau were recorded during the survey of the 5 ahupua ' $a$; 2 in coastal Pahinahina (which are included in the list of 36 residences 
previously recorded by O'Connor [1998]), 278 in coastal and upland Makiloa, 24 in coastal Kālala, 7 in upland Kaiholena, and 9 in coastal and upland Makeanehu.

\section{EXCAVATION, ARTIFACT AND FAUNAL ANALYSIS, AND ABSOLUTE DATING METHODS}

In a recent critique of dating programs in Hawai' $i$, Dye (2011) suggests that a more focused and rigorous method of excavation and documentation is required to determine a clear association between subsurface cultural deposits and surface architecture. Based upon his study of the coastal portions of the ahupиa ' $a$ of Kaiholena, Dye argues that episodes of reconstruction were common in prehistoric Hawai' $i$, and surface architecture may be temporally disassociated with adjacent and abutting cultural deposits. Dye outlines a method of stratigraphic and architectural recording and a Bayesian approach to ${ }^{14} \mathrm{C}$ dating that is designed to assess the integrity of surface features and associated deposits (2011:93-155). Primarily, this method relies on excavation beneath the basal stones of architectural components, and assessment of the deposits that are in an inferior position. Dye argues that cultural deposits directly beneath basal stones indicate depositional events that occurred prior to the construction of the surface architecture; in addition an absolute date from this deposit indicates a terminus ante quem age for the construction event of the surface architecture, although this can only be extended to the component itself (i.e. abutting walls, nearby hearths, or other features cannot be similarly associated, as they may have been constructed earlier or later in time). According to Dye's dating protocol, cultural deposits identified solely from excavations in the middle of enclosures or other large structures cannot be securely associated with the surface architecture, as the direct stratigraphic association of deposits and architecture is undetermined. In these cases, absolute dates indicate the age of cultural activities that produced the dated material, but not necessarily the age of the adjacent architecture.

In application, Dye describes the placement of excavation units against the interior faces of architectural components, as this location allows for the determination of the association of the deposits and the surface architecture (2011:119). He also advocates the extraction of multiple dating samples from several locations in an archaeological site, as this allows for the determination of sequential construction events. Coinciding with Dye's protocol, our dating program placed multiple excavations within the interior floor spaces of structures, often abutting the interior face of surface architecture (Table 1). Excavation of these areas was designed to sample the cultural material, determine the age of subsurface hearth features, stone pavings, and basal cultural deposits, and to assess the relationship between the deposits and the surface architecture. We also frequently excavated beneath the basal stones of the surface architecture, in order to assess the presence/absence of cultural materials that may have been deposited prior to construction. Our excavations within the interiors of structures sought to examine the deposits for evidence of pole and thatch construction, which may have existed prior to the construction of stone walls and be detectable by the presence of posthole features in the basal deposits.

Excavation units ranged in size from $50 \times 50 \mathrm{~cm}^{2}$ to $2 \times 2 \mathrm{~m}^{2}$, and extended from 10 to $80 \mathrm{~cm}$ in depth. The stratigraphic association of deposits was recorded in the field, and in instances where the excavation abutted the surface architecture, the relationship between the cultural deposits, the surface architecture, postholes, and the sterile substrate was recorded (Table 1). Excavated deposits were sieved with 1/8th and 1/16th inch mesh, and all artifacts (lithics, tools, mollusk and echinoderm shell, fish and mammal bone) were collected and later analyzed in the archaeology laboratories of The Ohio State University, B P Bishop Museum, and University of California, Berkeley. A total of 78 units were excavated, sampling 57 residential features. All residential features were also recorded with GPS survey points, and detailed plane table maps were generated to record surface architecture, isolated artifacts, and elevations (Field et al. 2008, 2009, 2010a). 


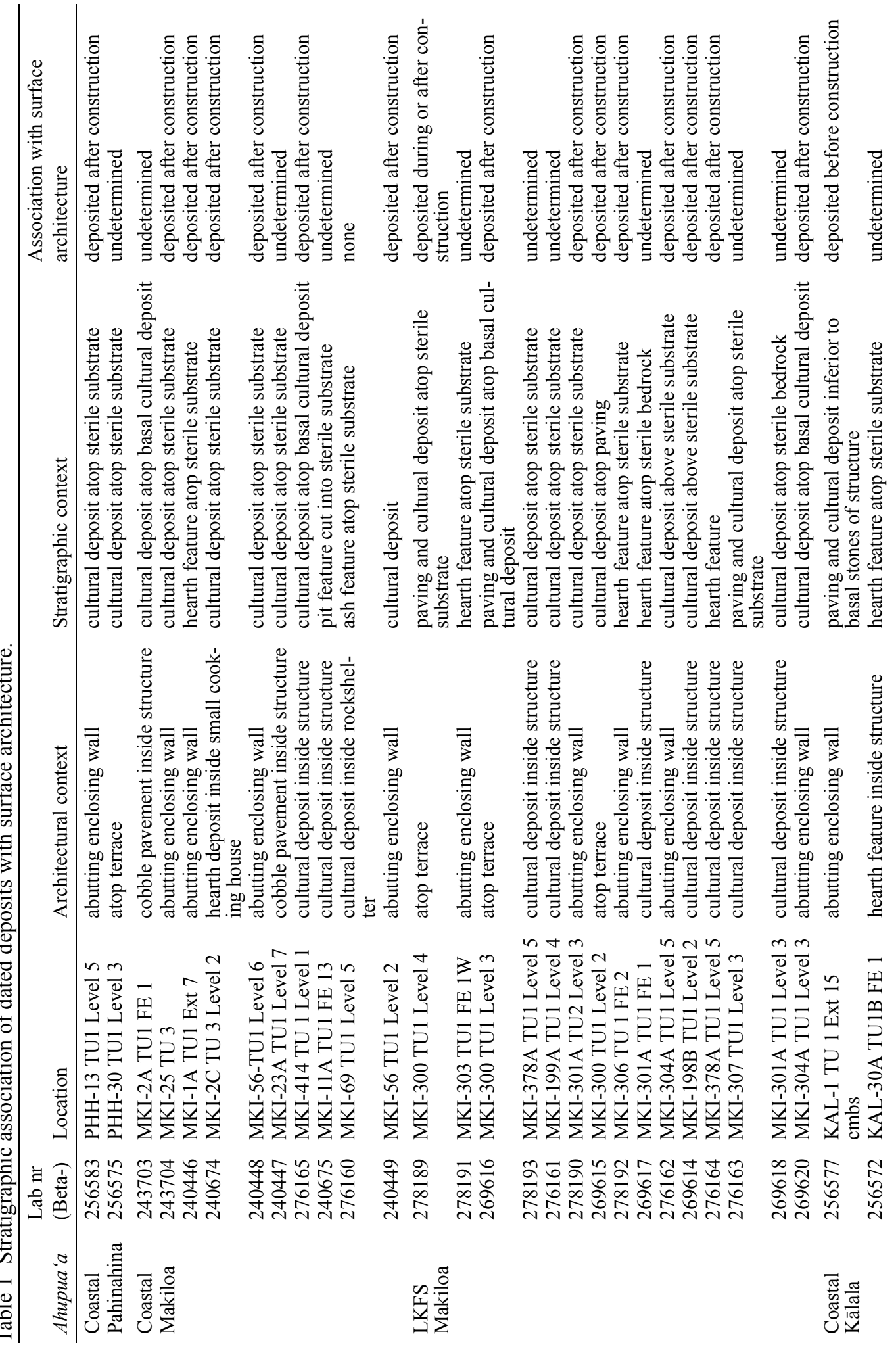




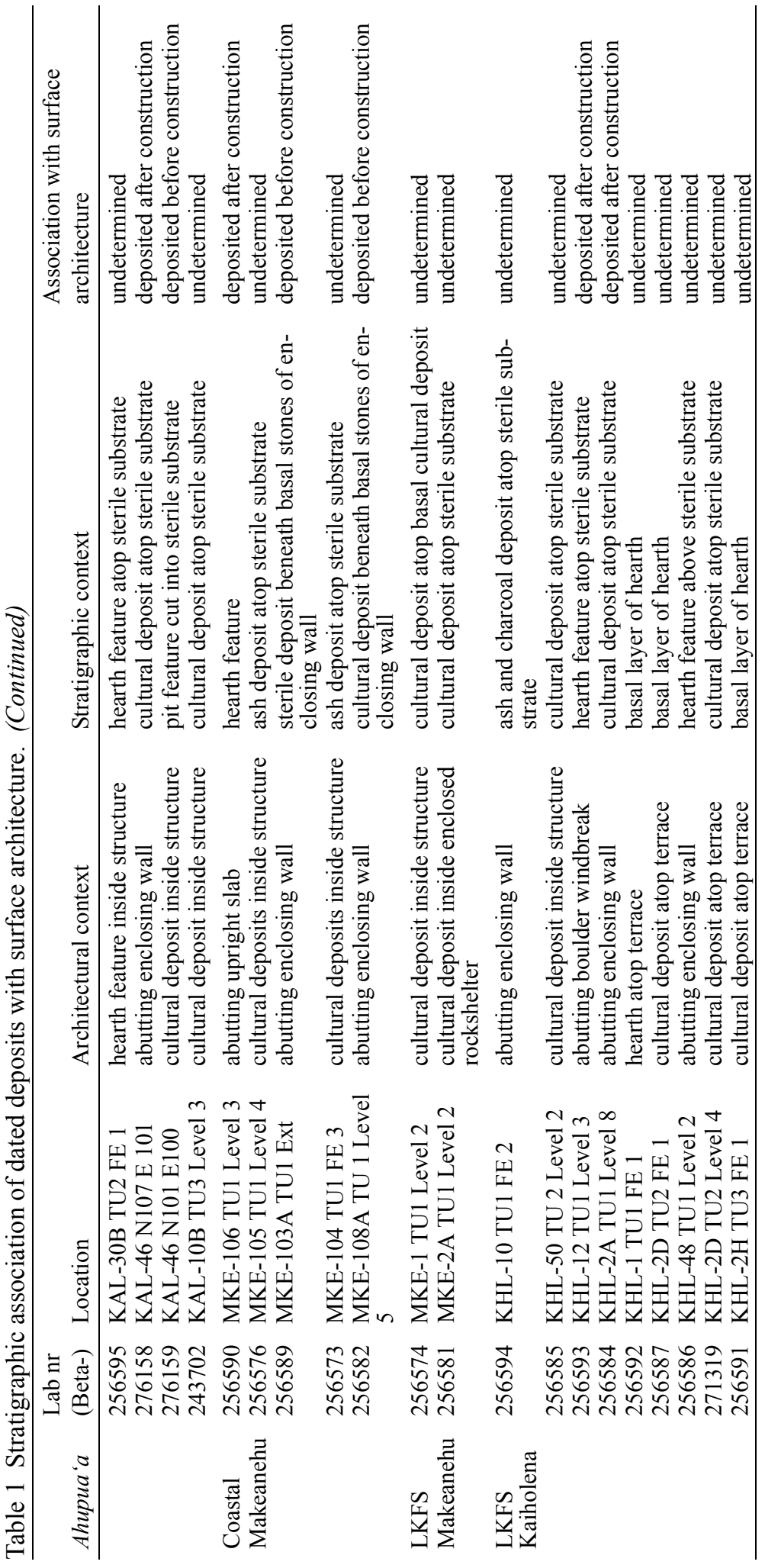




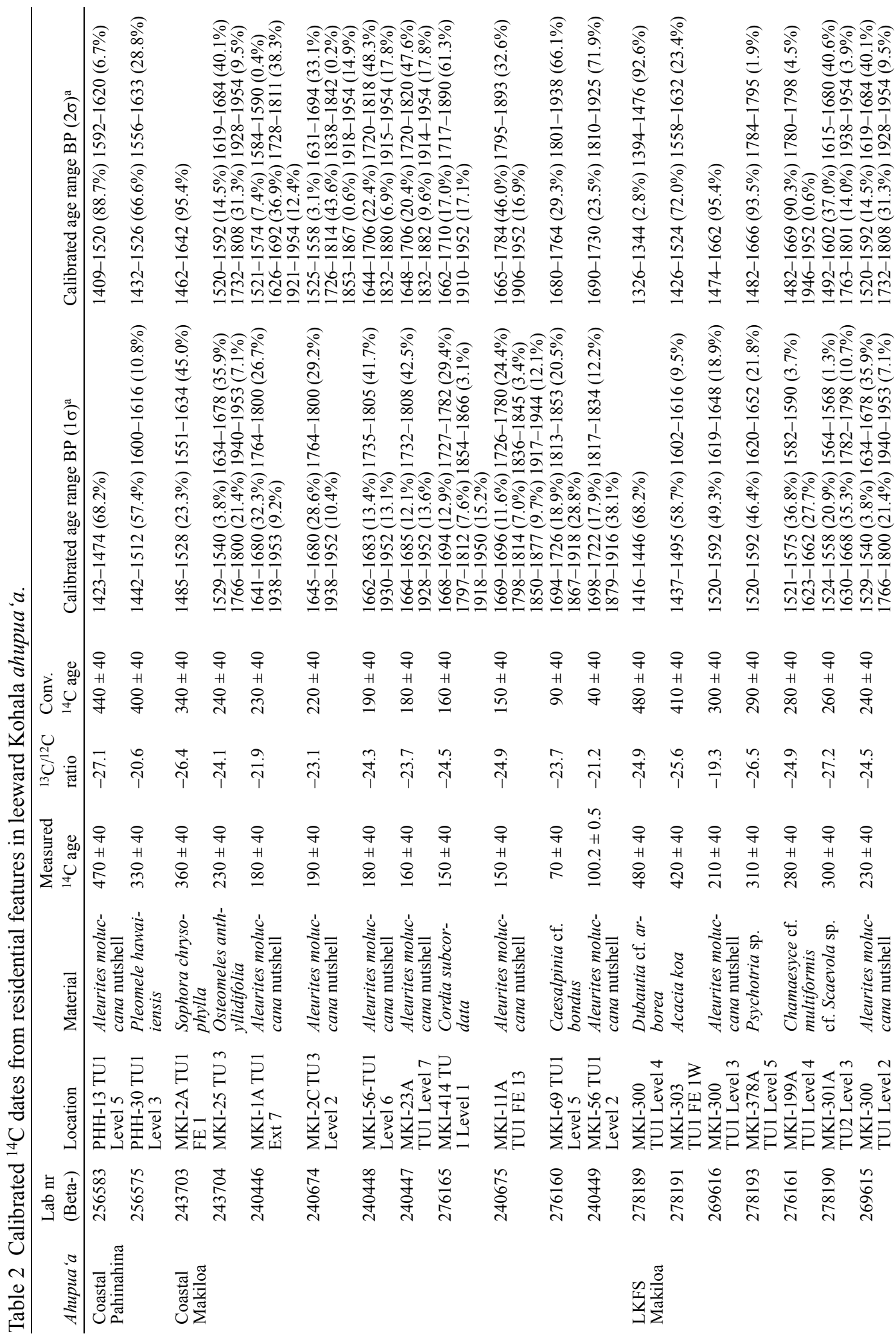




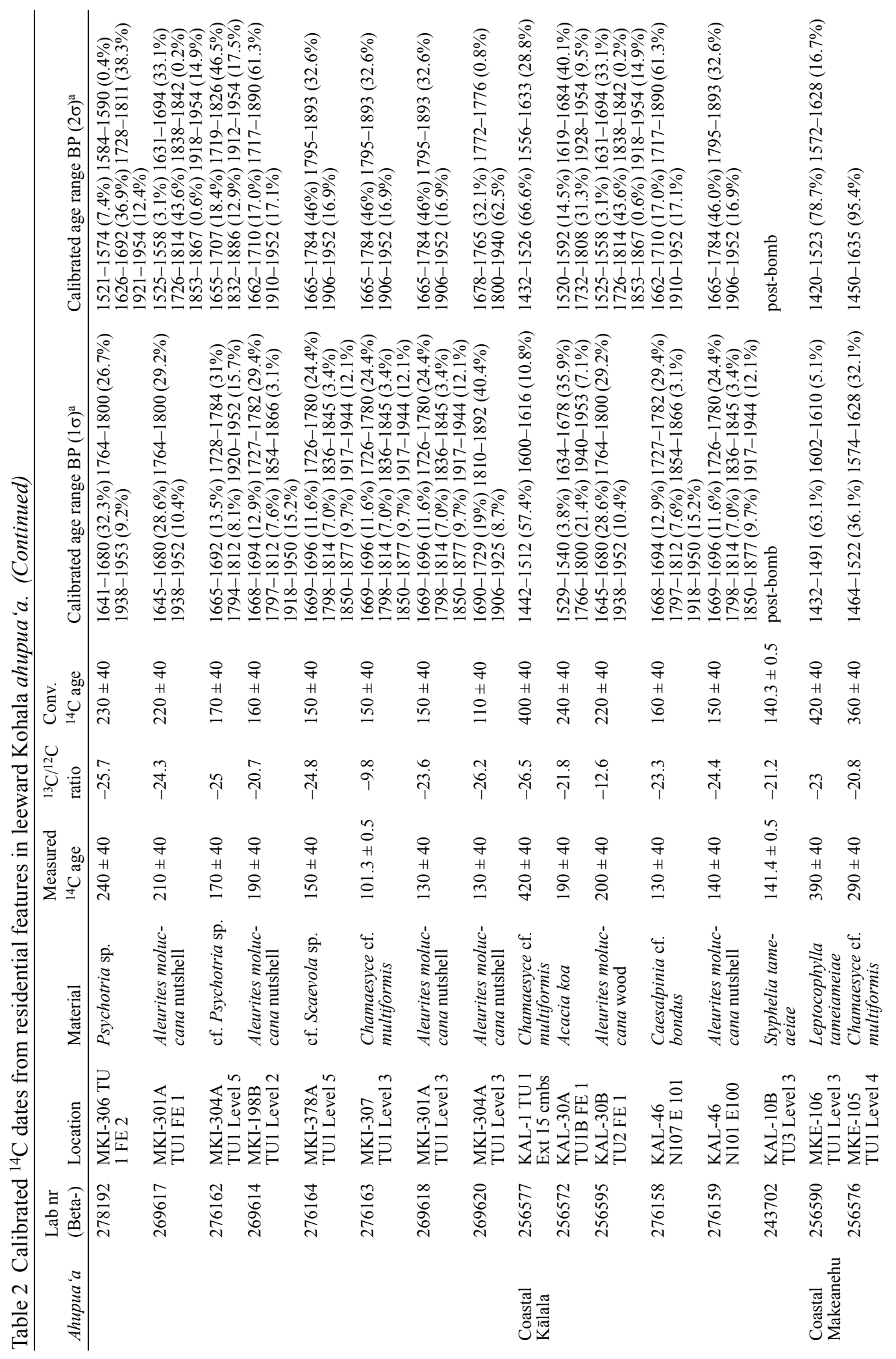


$614 \quad J$ S Field et al.

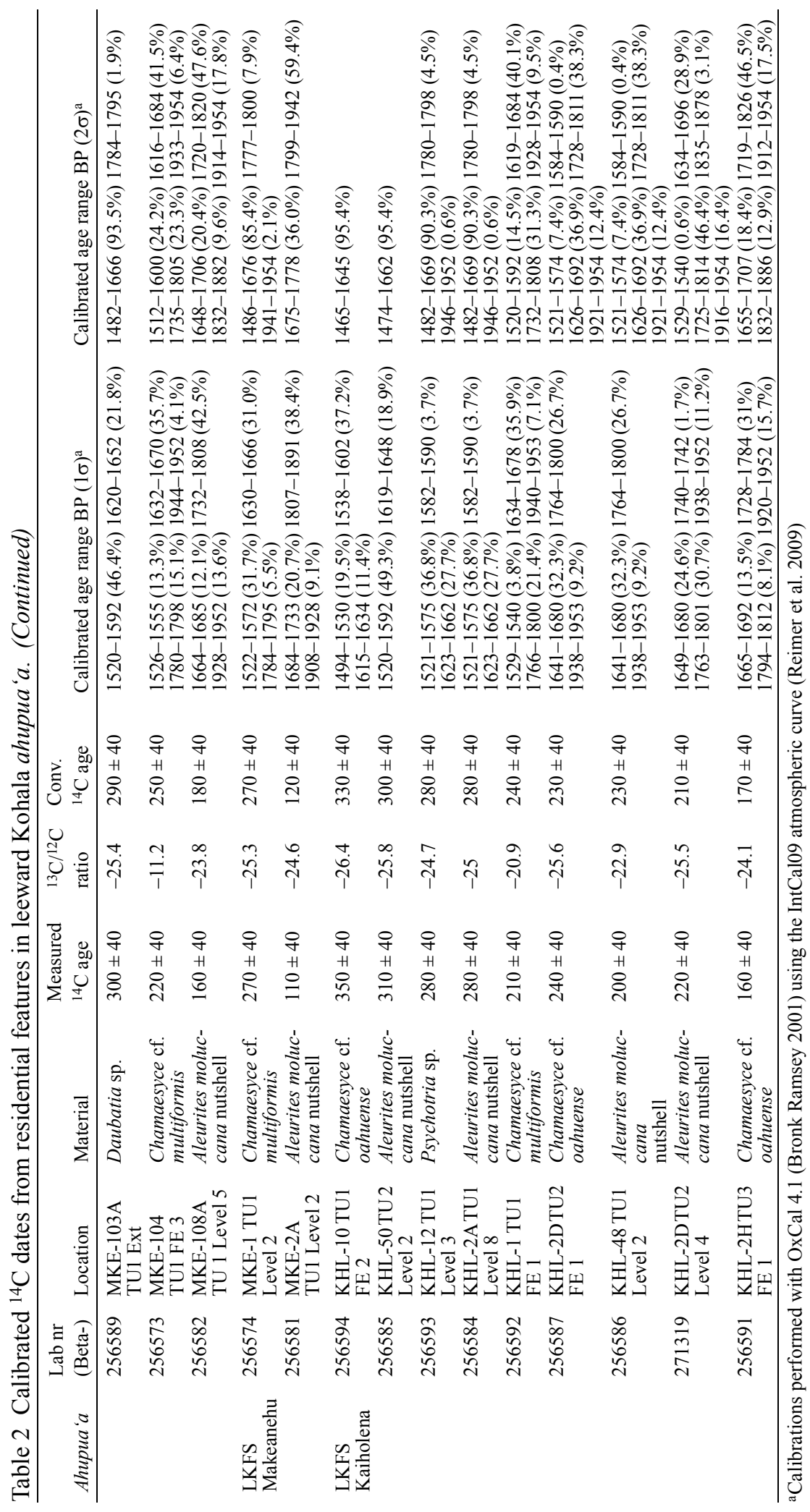


The relatively short chronology for human occupation in Hawai' $i$ necessitates steps to reduce possible error and to achieve the greatest possible accuracy and precision in the ${ }^{14} \mathrm{C}$ dating of archaeological features. In the past, charcoal from Hawaiian sites was often dated without obtaining botanical identifications, resulting in the frequent dating of longer-lived wood whose ${ }^{14} \mathrm{C}$ age may have been considerably older than the "target age" of the time of cultural use and burning. To avoid this problem, 46 of the $49{ }^{14} \mathrm{C}$ age determinations from our project were generated from samples that were identified as short-lived shrubs or annually produced nutshells. Carbonized plant materials were identified by M Jeraj (University of Wisconsin) using a reference collection of Hawaiian plants and wood. Selected samples were also chosen for their association with specific target events, such as the use of a combustion feature (an activity associated with residential occupation), scattered charcoal from beneath the basal stones of surface architecture (cultural material deposited prior to the construction of the surface architecture), charcoal from within the stones of a terrace paving (cultural material deposited during or just before the construction of the paving), or the deepest cultural deposit atop a sterile substrate (the first use of that location by people, but not necessarily associated with later architectural components or surface features). Forty-nine age determinations, retrieved from 36 residential features and 2 heiau, were obtained from the excavations. All samples were submitted to Beta Analytic for analysis using accelerator mass spectrometry (AMS) and the resulting determinations were calibrated in OxCal 4.1 (Bronk Ramsey 2001, 2009) using the IntCal09 atmospheric curve (Reimer et al. 2009). The resulting calibrations are listed in Table 2.

In addition, 5 coral samples recovered from residential features and heiau in the study area were dated by U-series via thermal ionization mass spectrometry (TIMS) at the Berkeley Geochronology Center. Analytical methods and corrections for minor amounts of initial ${ }^{230} \mathrm{Th}$ were carried out following techniques described in Sharp et al. (2010). All 5 coral samples meet geochemical criteria for reliable coral ages; that is, the corals have $\mathrm{U}$ and Th concentrations and back-calculated initial ${ }^{234} \mathrm{U} /$ ${ }^{238} \mathrm{U}$ ratios similar to modern corals (Table 3 ). The dated corals consist of broken branches of the genus Pocillopora, which is common along Hawaiian coastlines at shallow depths. Branch coral from the genus Pocillopora was used by ancient Hawaiians as a material for dedicatory offerings, and it was regularly collected as a live specimen prior to being incorporated into wall and platform fill (Kirch and Sharp 2005). A critical aspect of using coral for archaeological dating is the determination of a fresh harvest context, as aged and waterworn coral is a common and long-lived component of beach gravels. The 5 dated samples all exhibit minimal wear, indicating that their age closely coincides with the introduction into the archaeological context from which they were collected.

Table $3{ }^{230} \mathrm{Th}$ dates and U-Th analytical data for corals. Errors are $95 \%$ confidence intervals. All isotope ratios are activity ratios. Uncorrected dates assume no initial ${ }^{230} \mathrm{Th}$. Corrected dates assume initial ${ }^{230} \mathrm{Th} / 232 \mathrm{Th}$ atom ratio $=4.5 \pm 2.3 \times 10^{6}$. Decay constants used are those of Cheng et al. (2000). Analyses were completed in 2008.

\begin{tabular}{llllllllll}
\hline & $\mathrm{U}$ & ${ }^{232} \mathrm{Th}$ & ${ }^{230} \mathrm{Th} /$ & $\left({ }^{232} \mathrm{Th} /{ }^{238} \mathrm{U}\right)$ & $\begin{array}{l}\left({ }^{230} \mathrm{Th} /{ }^{238} \mathrm{Th}\right) \\
\times 10^{3}\end{array}$ & ${ }^{234} \mathrm{U} /{ }^{238} \mathrm{U}$ & $\begin{array}{l}\text { Uncorrected Corrected } \\
\text { date }(\mathrm{AD})\end{array}$ & $\begin{array}{l}\text { Initial } \\
\text { date }(\mathrm{AD})\end{array}$ & $\left({ }^{234} \mathrm{U} /{ }^{238} \mathrm{U}\right)$ \\
\hline KAL-1-CS2 & 2.27 & 46.5 & 632 & $0.6751 \pm 1.7$ & $4.270 \pm 2.8$ & $1.151 \pm 0.34$ & $1602 \pm 12$ & $1603 \pm 12$ & $1.151 \pm 0.004$ \\
KAL-26-CS1 $^{\mathrm{a}}$ & 2.26 & 66.4 & 371 & $0.9675 \pm 0.9$ & $3.592 \pm 2.0$ & $1.151 \pm 0.564$ & $1667 \pm 7.2$ & $1667 \pm 7.2$ & $1.151 \pm 0.007$ \\
MKI-1-CS1 & 2.85 & 545 & 146 & $6.289 \pm 9.9$ & $9.209 \pm 7.9$ & $1.148 \pm 0.20$ & $1128 \pm 70$ & $1133 \pm 70$ & $1.148 \pm 0.002$ \\
MKI-23-CS1 & 2.60 & 261 & 194 & $3.308 \pm 3.8$ & $6.413 \pm 7.9$ & $1.145 \pm 0.154$ & $1395 \pm 49$ & $1397 \pm 49$ & $1.145 \pm 0.002$ \\
MKI-56-TUI- & 2.56 & 134 & 235 & $1.717 \pm 1.1$ & $4.031 \pm 1.1$ & $1.146 \pm 0.192$ & $1623 \pm 4.2$ & $1625 \pm 4.2$ & $1.146 \pm 0.002$ \\
EXT4 & & & & & & & & & \\
\hline
\end{tabular}

a The sample listed as KAL-26-CS1 was collected from the surface architecture of feature KAL-30A. 


\section{RESULTS: CHRONOLOGY OF RESIDENCE IN LEEWARD KOHALA}

Of the 49 AMS dates, 19 (38\%) were recovered from contexts in which the basal stones of the surface architecture and the cultural deposits rested on the same sterile basal substrate. As these contexts were all within the interiors of enclosures, we interpret this relationship as one of construction followed by cultural deposition, although we cannot be certain of the amount of time that separates these 2 events (Table 1). However, we argue that their direct contact with the same sterile substrate indicates a minimal amount of time between those events, and therefore the age of the base architecture is close to the age of initial cultural deposition. Twelve of the AMS dates were recovered from the deepest cultural deposits of these contexts, indicating a maximum age for occupation at that location. Seven were from features or deposits that were in shallower layers, and therefore date later occupation.

Twenty-four (48\%) of the AMS dates were recovered from subsurface cultural deposits that were within the interiors of structures; therefore, their association with nearby surface architecture cannot be directly determined. In these instances, the AMS dates indicate the age of the cultural activity that produced the deposit. As these are midden deposits with abundant remains of food debris, tool-making fragments, and charcoal from burning or cooking activities, they are undoubtedly the product of occupation, regardless of whether or not they are contemporaneous with the surface architecture. Nineteen of the AMS dates were recovered from the deepest cultural deposits, indicating a maximum age for occupation at that location. Five were from later deposits.

Only $4(8 \%)$ of the AMS dates were obtained from cultural deposits that were below the basal stones of the surface architecture. The excavations that produced these samples all abutted surface architecture, and revealed cultural deposits extending beneath the basal stones. The dates from these deposits provide a terminus ante quem for the date of construction for the surface architecture. However, the earlier occupations and deposits at these sites may not be related to the construction event.

All of the coral samples, with the exception of MKI-56-TU1-EXT4, were recovered from the surface of the stone walls that constitute the surface components of the residential features. The MKI56 sample was recovered from an excavation that extended under the basal stones of the structure, and thus this sample provides a terminus ante quem for the date of construction. Sample KAL-26CS1 retains its delicate surface structures, indicating that it was harvested as a living coral from the sea. We interpret its U-series date, $\mathrm{AD} 1667 \pm 7.2 \mathrm{yr}$ (all U-series age errors are quoted at $2 \sigma$ ), to closely coincide with introduction into the archaeological context from which it was collected (Table 3). The 4 other dated samples exhibit minor wear on their outer surfaces, probably the result of brief residence in the surf zone. Thus, we interpret their U-series dates as maximum ages for introduction into their archaeological contexts.

The oscillations of the IntCal09 atmospheric ${ }^{14} \mathrm{C}$ calibration curve over the last 500 yr pose a problem for Hawaiian archaeological chronology due to the multiple intercepts for calibrated calendar dates, and to the marked aggregation of dates into 2 distinct age ranges following calibration. These age ranges roughly coincide with the years AD 1400-1620 and 1660-1950. However, the $2 \sigma$ probability values (Table 2) for calibrated AMS dates indicate differential likelihood for particular age ranges. Using $70 \%$ as a minimum distribution, we generated 3 chronological periods to bracket the dates from the sampled residences. We define Period I as ranging from AD 1400-1520, Period II from AD 1520-1650, and Period III from AD 1650-1800. We employ these chronological periods as analytical units for the examination of deposits within residential features over time. A summary description of each of the excavated residences and their inclusion in each of the chronological periods is listed in Table 4. 
Table 4 Data pertaining to surface architecture associated with the dated samples.

\begin{tabular}{|c|c|c|c|c|c|}
\hline Ahupua'a & Feature & Description & Interior space $\left(\mathrm{m}^{2}\right)$ & $\begin{array}{l}\text { Chrono- } \\
\text { logical } \\
\text { period }\end{array}$ & $\begin{array}{l}\text { Associated } \\
\text { dates }\end{array}$ \\
\hline \multirow{2}{*}{$\begin{array}{l}\text { Coastal } \\
\text { Pahinahina }\end{array}$} & PHH-13 & Heiau & 120 & I & Beta-256583 \\
\hline & PHH-30 & Terrace, windbreak & 24 & I & Beta- 256575 \\
\hline \multirow[t]{8}{*}{$\begin{array}{l}\text { Coastal } \\
\text { Makiloa }\end{array}$} & MKI-2 & $\begin{array}{l}\text { Terrace, windbreak, abut- } \\
\text { ting larger enclosure }\end{array}$ & $\begin{array}{l}22 \text { (enclosure) } \\
578 \text { (large enclosure) }\end{array}$ & II/III & $\begin{array}{l}\text { Beta-243703 } \\
\text { Beta-240674 }\end{array}$ \\
\hline & MKI-25B & $\begin{array}{l}\text { Enclosure, abutting larger } \\
\text { enclosure }\end{array}$ & 28 & III & Beta-243704 \\
\hline & MKI-1A & $\begin{array}{l}\text { Small enclosure with at- } \\
\text { tached shelter }\end{array}$ & 7 & III & $\begin{array}{l}\text { Beta-240446 } \\
\text { MKI-1-CS1 }\end{array}$ \\
\hline & MKI-23A & Enclosure & 26 & III & $\begin{array}{l}\text { Beta-240447 } \\
\text { MKI-23-CS1 }\end{array}$ \\
\hline & MKI-56 & $\begin{array}{l}\text { Large monumental enclo- } \\
\text { sure }\end{array}$ & 84 & III & $\begin{array}{l}\text { Beta-240448 } \\
\text { Beta-240449 } \\
\text { MKI-56- } \\
\text { TU1-EXT4 }\end{array}$ \\
\hline & MKI-69 & Enclosure/rockshelter & 30 & III & Beta-276160 \\
\hline & MKI-11A & $\begin{array}{l}\text { Enclosure with attached } \\
\text { shelter }\end{array}$ & 21 & III & Beta-240675 \\
\hline & MKI-414 & Small enclosure & 1 & III & Beta-276165 \\
\hline \multirow{9}{*}{$\begin{array}{l}\text { LKFS } \\
\text { Makiloa }\end{array}$} & MKI-199A & Enclosure & 28 & II & Beta-276161 \\
\hline & MKI-303 & Small enclosure & 7 & I & Beta-278191 \\
\hline & MKI-306 & Terrace, windbreak & 30 & III & Beta-278192 \\
\hline & MKI-300 & Paved platform & 15 & I/II/III & $\begin{array}{l}\text { Beta-278189 } \\
\text { Beta-269616 } \\
\text { Beta-269615 }\end{array}$ \\
\hline & MKI-301A & $\begin{array}{l}\text { Large enclosure with in- } \\
\text { ner terrace }\end{array}$ & 416 & II/III & $\begin{array}{l}\text { Beta-278190 } \\
\text { Beta-269617 } \\
\text { Beta-269618 }\end{array}$ \\
\hline & MKI-378A & $\begin{array}{l}\text { Small enclosure with at- } \\
\text { tached terrace }\end{array}$ & 9 & II/III & $\begin{array}{l}\text { Beta-278193 } \\
\text { Beta-276164 }\end{array}$ \\
\hline & MKI-304A & Small enclosure & 12 & III & $\begin{array}{l}\text { Beta- } 276162 \\
\text { Beta-269620 }\end{array}$ \\
\hline & MKI-198B & $\begin{array}{l}\text { Large enclosure with in- } \\
\text { ner terrace }\end{array}$ & 100 & III & Beta-269614 \\
\hline & MKI-307 & Small enclosure & 14 & III & Beta-276163 \\
\hline \multirow[t]{5}{*}{$\begin{array}{l}\text { Coastal } \\
\text { Kālala }\end{array}$} & KAL-1 & Heiau & 100 & I & $\begin{array}{l}\text { Beta-256577 } \\
\text { KAL-1-CS2 }\end{array}$ \\
\hline & KAL-30A & Terrace, windbreak & 21 & II & $\begin{array}{l}\text { Beta-256572 } \\
\text { KAL-26-CS1 }\end{array}$ \\
\hline & KAL-30B & Enclosure & 10 & III & Beta-256595 \\
\hline & KAL-46 & $\begin{array}{l}\text { Large monumental enclo- } \\
\text { sure }\end{array}$ & 85 & III & $\begin{array}{l}\text { Beta-276158 } \\
\text { Beta-276159 }\end{array}$ \\
\hline & KAL-10B & Small C-shape shelter & 3 & III & Beta-243702 \\
\hline \multirow{5}{*}{$\begin{array}{l}\text { Coastal } \\
\text { Makeanehu }\end{array}$} & MKE-105 & Small enclosure & 16 & II & Beta-256576 \\
\hline & MKE-106 & Windbreak, lithic scatter & 26 & I & Beta- 256590 \\
\hline & MKE-103A & $\begin{array}{l}\text { Large enclosure with in- } \\
\text { ner terrace }\end{array}$ & $\begin{array}{c}20 \text { (terrace) } \\
165 \text { (enclosure) }\end{array}$ & II & Beta-256589 \\
\hline & MKE-104 & $\begin{array}{l}\text { Terrace atop boulder out- } \\
\text { crop, abutting larger en- } \\
\text { closure }\end{array}$ & $\begin{array}{c}4 \text { (terrace) } \\
350 \text { (enclosure) }\end{array}$ & II & Beta-256573 \\
\hline & MKE-108A & Large enclosure & 130 & III & Beta-256582 \\
\hline $\begin{array}{l}\text { LKFS } \\
\text { Makeanehu }\end{array}$ & MKE-1 & $\begin{array}{l}\text { Large enclosure with in- } \\
\text { ner terrace }\end{array}$ & $\begin{array}{l}140 \text { (terrace) } \\
448 \text { (enclosure) }\end{array}$ & II & Beta-256574 \\
\hline
\end{tabular}


Table 4 Data pertaining to surface architecture associated with the dated samples.

\begin{tabular}{|c|c|c|c|c|c|}
\hline Ahupua'a & Feature & Description & Interior space $\left(\mathrm{m}^{2}\right)$ & $\begin{array}{l}\text { Chrono- } \\
\text { logical } \\
\text { period }\end{array}$ & $\begin{array}{l}\text { Associated } \\
\text { dates }\end{array}$ \\
\hline & MKE-2A & $\begin{array}{l}\text { Rockshelter, abutting } \\
\text { larger enclosure }\end{array}$ & $\begin{array}{l}10 \text { (rockshelter) } \\
620 \text { (enclosure) }\end{array}$ & III & Beta-256581 \\
\hline LKFS & KHL-10 & Small U-shape shelter & 4 & I & Beta-256594 \\
\hline \multirow[t]{7}{*}{ Kaiholena } & KHL-2A & Enclosure & 48 & II & Beta-256584 \\
\hline & KHL-50 & $\begin{array}{l}\text { Large enclosure with in- } \\
\text { ner terrace }\end{array}$ & $\begin{array}{c}47 \text { (terrace) } \\
260 \text { (enclosure) }\end{array}$ & II & Beta-256585 \\
\hline & KHL-12 & Terrace, windbreak & 3 & II & Beta-256593 \\
\hline & KHL-48 & $\begin{array}{l}\text { Large enclosure with in- } \\
\text { ner terrace }\end{array}$ & $\begin{array}{c}65 \text { (terrace) } \\
328 \text { (enclosure) }\end{array}$ & III & Beta-256586 \\
\hline & KHL-1 & $\begin{array}{l}\text { Large enclosure with in- } \\
\text { ner terrace }\end{array}$ & $\begin{array}{c}235 \text { (terrace) } \\
2500 \text { (enclosure) }\end{array}$ & III & Beta-256592 \\
\hline & KHL-2D & Terrace abutting outcrop & 16 & III & $\begin{array}{l}\text { Beta-256587 } \\
\text { Beta-271319 }\end{array}$ \\
\hline & KHL-2H & Terrace abutting outcrop & 8 & III & Beta-256591 \\
\hline
\end{tabular}

Our suite of dates indicates that only 5 deposits associated with residence and ritual architecture date to Period I (AD 1400-1520). These occupations were located along the coast near prominent bays (PHH-13, PHH-30, KAL-1), and within the central portion of the inland area that would become the LKFS (MKI-303, KHL-10) (Figure 2). The ${ }^{14} \mathrm{C}$ date for the heiau KAL-1 was obtained from cultural deposits that were directly inferior to surface architecture, providing a terminus ante quem date (AD 1432-1633) for construction. However, surface coral from KAL-1 suggests a maximum age of AD $1603 \pm 12$ for the placement of the coral on the heiau. KAL-1 is located in Kālala alongside the Kālala and Makiloa ahupua' $a$ boundary, and these bracketing dates suggest that the heiau was established and used between AD 1400-1600. Its position on the border also indicates a potential age for the establishment of those ahириа ' $a$ as separate socioeconomic units (see Discussion).

The other deposits that date to this period indicate cultural activities that occurred after the construction of the surface architecture, such as the heiau within Pahinahina ahupua 'a (PHH-13). Others are from undetermined contexts within the interiors of small $\left(<30 \mathrm{~m}^{2}\right)$ structures (PHH-30, MKI-303, KHL-10). The small size of the structures associated with these deposits suggests that Period I marks a time of early settlement in leeward Kohala, which was initiated by single household units. Artifacts and faunal remains within these deposits indicate that coastal households were focused on fishing and the extraction of marine resources (Field et al. 2010b:74). In the uplands, occupations that date to Period I were located within areas of moderate rainfall, and in association with the earliest trails and agricultural alignments (Field et al. 2011:7330). However, the identification and dating of a carbonized fragment of probable sweet potato (Ipomea batatas) (Ladefoged et al. 2005) indicates that cultivation (and perhaps associated occupation) in the LKFS occurred during and perhaps slightly prior to Period I. Ladefoged and Graves (2008) suggest that cultivation in the southern portion of the field system began "as early as AD 1290 and certainly by AD 1430" (2008:779). The deposits identified from Period I in the LKFS were likely established as the first farmsteads following the initial development of the area for cultivation.

Deposits that date to Period II (AD 1520-1650) were encountered more frequently along both the coast and within the field system, indicating an increase in the overall number of residences, and also an increase in the number of newly established residences (Figure 3). Within the field system, 2 are contexts that postdate the establishment of residential architecture (KHL-12, KHL-2a), and 4 are from undetermined contexts (MKI-378A, MKI-199A, MKI-301A, KHL-50). Along the coast, 

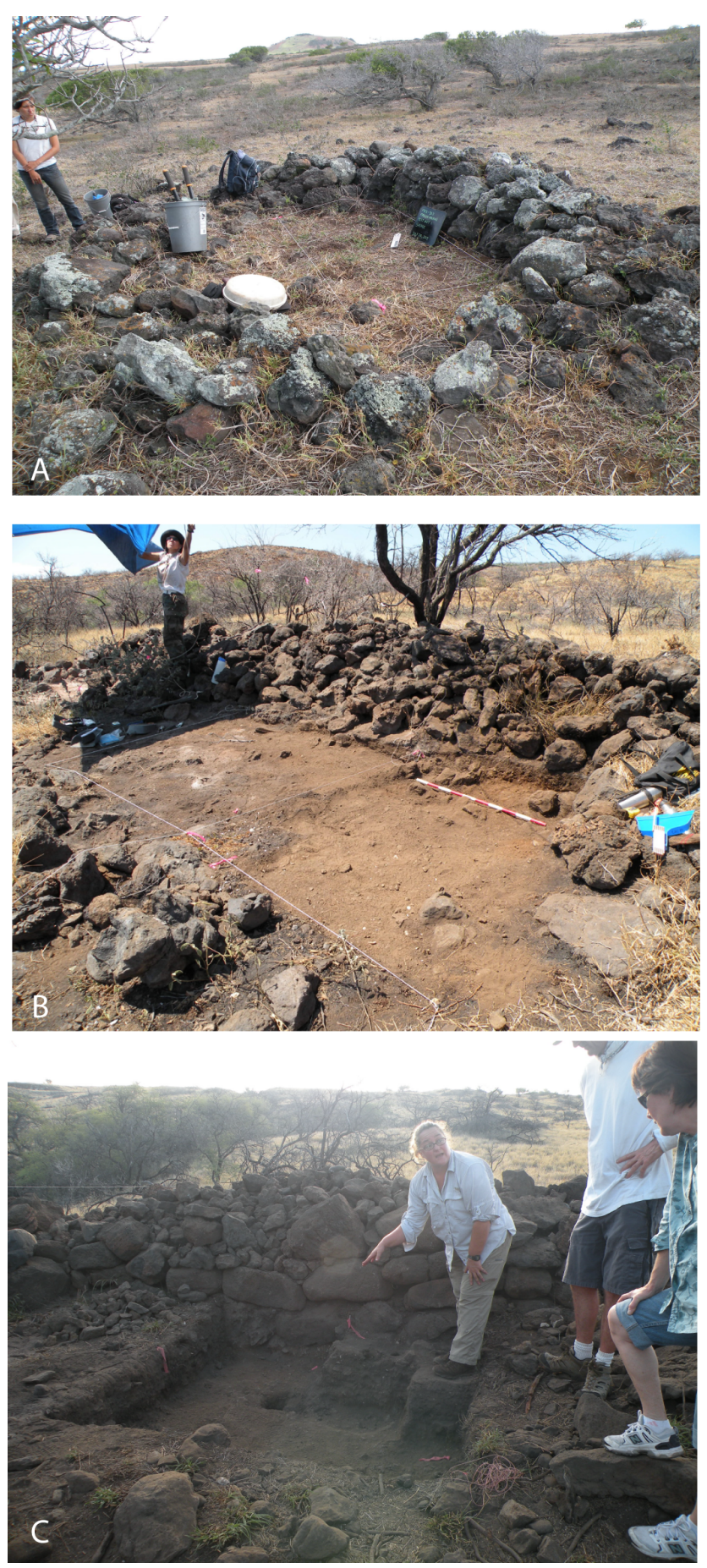

Figure 2 Examples of surface architecture in study area: A) Small enclosure from within the field system (MKI303), basal cultural deposit dates to Period I; B) Large terrace with windbreak wall, from coast (KAL-30A); hearth features date to Period II; C) Large enclosure with massive walls and basal stones (MKI-56); coral from beneath wall dates structure to Period III. 
hearths and other features from within the structures KAL-30A, MKE-105, and MKE-104 date the occupation of residences to this period. Deposits from beneath the basal stones of MKE-103A are the only deposits that predate the construction of the surface architecture. Analysis of architecture and settlement patterns, as well as multiple dates from smaller associated structures, indicates that Period II was characterized by population growth and expansion, which was coupled with increased residence size (Field et al. 2010b), and also a greater diversity of associated smaller household structures. Surface corals (e.g. KAL-26-CS1) also indicate the larger residences were maintained and used in later centuries. These trends occur simultaneously along the coast and in the field system, indicating that population expansion and household growth was occurring at the ahupua' $a$ level. Examination of the absolute chronology of deposits within residences that abut agricultural alignments also indicates that the land within the field system was segmented into smaller units during this period, and that these were associated with the establishment of new residences (Field et al. 2011). These units likely represent traditional ' $i l i$, small land divisions that were farmed by individual households. This process of segmentation within ahupua 'a suggests a process of household fissioning fueled by population growth.

Period III (AD 1650-1800) deposits are the most abundant, and their association with surface architecture indicates that residential construction experienced a marked increase in the latest precontact century, and perhaps immediately postcontact (i.e. after AD 1779). We acknowledge that this increase must be partially due to sampling, as younger structures on the Kohala landscape are more visible, and more likely to be included in the survey and excavation sample. The deposits associated with these structures, and their placement along the coast $(n=12)$ and in the field system $(n=12)$, suggest a continuation of the process of household fission, with new occupations established at the lower (and drier) elevations of the field system, and also along coastal terraces away from bays (Figure 3). Nine dates are from deposits that immediately postdate the construction of the surface architecture (MKI-25B, MKI-1A, MKI-2C, MKI-56, MKI-301A, MKI-306, MKI-304A, MKI-198B, KAL-46), and 9 are from undetermined architectural contexts inside the structures (MKI-23A, MKI-11A, MKI-307, KAL-30B, KAL-10B, MKE-2A, KHL-48, and KHL-2D). Two dates are from beneath basal stones, and provide a terminus ante quem date for the construction of residential walls (KAL-46, MKE-108A). The architecture associated with these dated deposits was diverse during this final period, and included small- $\left(<30 \mathrm{~m}^{2}\right)$, medium- $\left(30-50 \mathrm{~m}^{2}\right)$, and large-sized enclosures $\left(>50 \mathrm{~m}^{2}\right)$. Surface architecture from MKI-1A and MKI-23A were topped with fragments of coral that predate $\mathrm{AD} 1500$, suggesting that these samples were obtained from the surf zone, and are older than the age of construction (Table 3).

In addition, coral and charcoal dates from immediately beneath the enclosing walls of structures MKI-56, KAL-46, and MKE-108A indicate that large monumental structures with high walls and elaborate construction were constructed during Period III. Deposits also revealed a rich cultural deposit of large-sized fish bones and fine tool fragments that were not encountered in deposits associated with smaller structures. This distinction suggests that the larger residences were constructed and used by elites (Field et al. 2010b:74). The restriction of these kinds of coastal residences to the latest period also indicates that elite influence and demands for costly monumental architecture and goods did not develop fully until after significant population growth in the region. In the field system, associated residential structures that date to Period III tended to consist of large enclosures and terraced outcrops (KHL-2D, KHL-48, MKI-301A). A few structures that are large in size and which have massive wall construction may also have been used for elite residence (MKI-198B). 

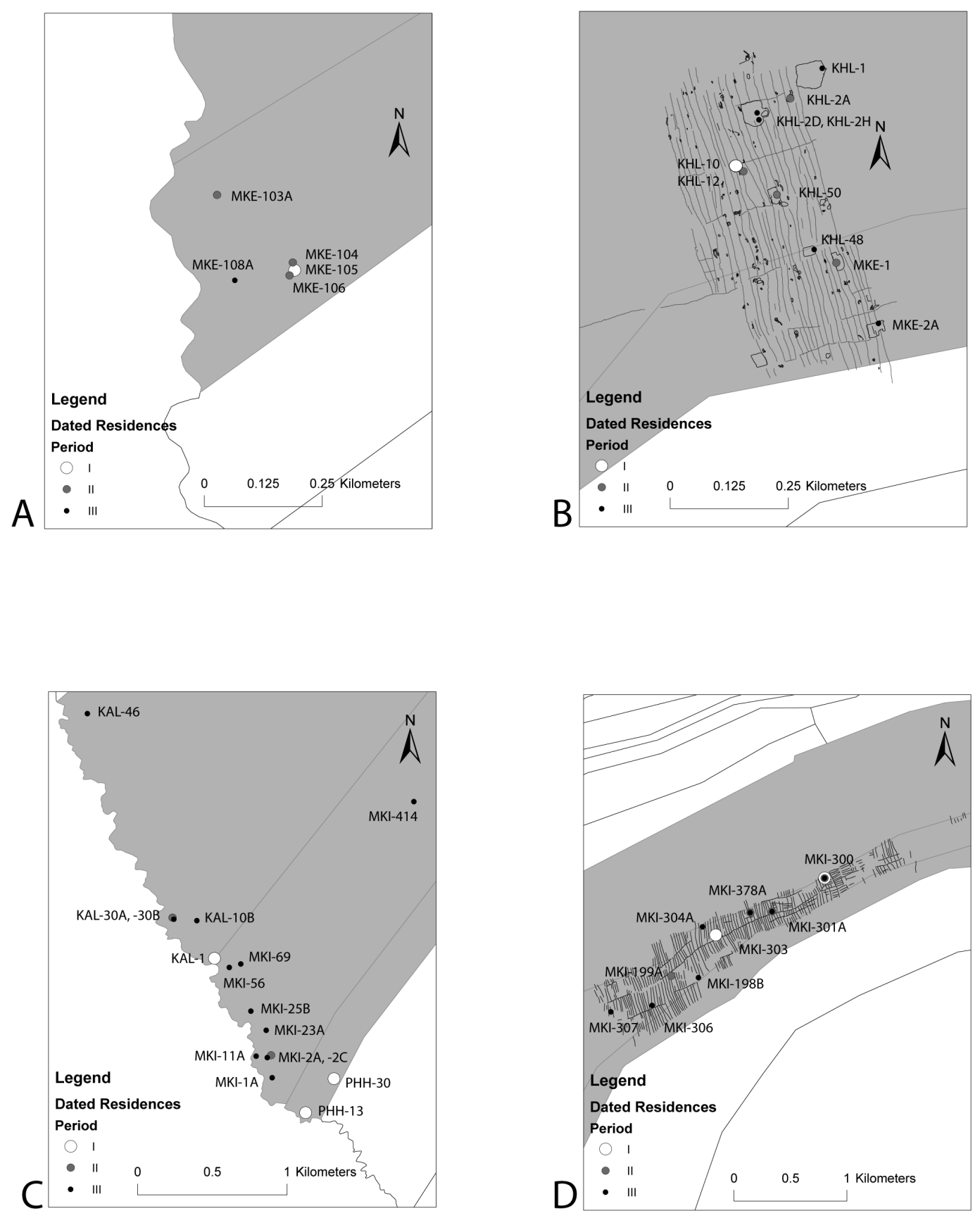

Figure 3 Residential feature distribution in (A) coastal Makeaneahu; (B) upland Kaiholena and Makeanehu; (C) coastal Kālala, Makiloa, and Pahinahina; and (D) upland Makiloa. Symbols indicate the age of dated deposits; sites with multiple dates are shown with overlapping symbols. The agricultural alignments and trails of the LKFS are shown insets B and D. The extent of alignments and trails shown is limited to the study area only. 


\section{COMPARISON: COASTAL AND FIELD SYSTEM HOUSEHOLD ECONOMICS}

Examination of marine and terrestrial fauna supports the hypothesis that the earliest phase of settlement in leeward Kohala was initiated by small social units, most likely extended family households, who settled along the coast and in the uplands and focused on local resource extraction and production. During Period I (AD 1400-1520), the occupants of coastal residences procured abundant marine mollusks and echinoderms for subsistence, amounting to over $1.3 \mathrm{~kg}$ and 21 taxa from $0.54 \mathrm{~m}^{3}$ of excavated deposits (Table 5). The remains of dog, rat, and pig are completely absent, which suggests that these resources were not raised or imported to the coast during this period (Table 6). In Hawai' $i$, dogs and pigs were raised for their meat, and would have required a steady supply of sweet potato, taro, or other fodder in order to reach adult size. As the arid climate of the coast is unsuited to growing these crops, the absence of pig and dog indicates that these foods were probably not available in large amounts to coastal populations during this period. In contrast, excavation of residential features in the field system indicates that marine mollusks were rare $(<1 \mathrm{~g}$, and only 1 taxon represented), despite the much larger sample size $\left(1.99 \mathrm{~m}^{3}\right)$. Instead, dog bone, pig bone, rat bone, and unidentified fragments of medium mammal (either dog or pig) were recovered in small amounts from deposits that date to AD 1400-1520. The presence of these animals coupled with the absence of marine mollusks provides a proxy measure of subsistence for inland residences: agricultural production at the household level with little connection to coastal resources.

Table 5 Frequency of marine mollusks and echinoderm shell (g), and number of identified taxa from deposits associated with residential features on the coast and within the field system during temporal periods I-III. The area of excavation $\left(\mathrm{m}^{3}\right)$ that produced the assemblage is indicated within the column heading.

\begin{tabular}{llll}
\hline Coast & $\begin{array}{l}\text { AD 1400-1520 } \\
(0.54)\end{array}$ & $\begin{array}{l}\text { AD 1520-1650 } \\
(1.61)\end{array}$ & $\begin{array}{l}\text { AD 1650-1800 } \\
(1.34)\end{array}$ \\
\cline { 2 - 4 } Total grams & 1346.56 & 426.16 & 2158.71 \\
N Taxa & 21 & 35 & 46 \\
\hline LKFS & AD 1400-1520 & AD 1520-1650 & AD 1650-1800 \\
& $(1.99)$ & $(3.90)$ & $(9.25)$ \\
\cline { 2 - 4 } Total grams & 0.43 & 12.61 & 500.32 \\
N Taxa & 1 & 14 & 15 \\
\hline
\end{tabular}

After AD 1520, the transfer of resources from the coast to the field system, and vice versa, indicates that household subsistence and ahupua 'a economics had begun to change. In both the central (Kaiholena-Makeanehu) and southern (Kālala-Makiloa-Pahinahina) portions of the field system, the number of residences in the field system increased, and these were associated with the segmentation of agricultural alignments and the establishment of new trails. This settlement pattern suggests a process of household fissioning and population growth, which stabilized in the central portion of the field system before $\mathrm{AD} 1650$, and continued to increase in the south until the contact period (Field et al. 2011). The remains of marine mollusks also appear in greater amounts $(12.61 \mathrm{~g})$ in inland residential feature deposits that postdate $\mathrm{AD} 1520$, indicating increased access to the coast. The larger amounts of marine shell from inland residential features dating to Period III (AD 1650-1800) deposits are correlated to increased sample size, although the number of taxa recovered from field system residential deposits remains unchanged from Period II.

Although the excavation sample size from the coast is relatively similar between periods II and III, the number of marine mollusk taxa increases from 35 to 46 during this interval, indicating a broad- 
Table 6 Frequency of commensal animals (g) from residential features on the coast and within the field system during temporal periods I-III. The area of excavation $\left(\mathrm{m}^{3}\right)$ that produced the assemblage is indicated within the column heading.

\begin{tabular}{llllllc}
\hline Coast & & & & & & \\
& AD 1400-1520 & & AD 1520-1650 & & AD 1650-1800 \\
& $(0.54)$ & $\%$ & $(1.61)$ & $\%$ & $(1.34)$ & $\%$ \\
\cline { 2 - 7 } Canis familiaris & 0 & 0 & 0 & 0 & 12.99 & 41.3 \\
Rattus sp. & 0 & 0 & 0.01 & 0.2 & 0.64 & 2 \\
$\begin{array}{l}\text { Sus scrofa } \\
\text { Unidentified medium }\end{array}$ & 0 & 0 & 0.25 & 6 & 1.16 & 3.7 \\
mammal & 0 & 0 & 3.92 & 93.8 & 16.65 & 53 \\
Total & 0 & 0 & 4.18 & 100 & 31.44 & 100 \\
\hline LKFS & AD 1400-1520 & & AD 1520-1650 & & AD 1650-1800 \\
& $(1.99)$ & $\%$ & $(3.90)$ & $\%$ & $(9.25)$ & $\%$ \\
Canis familiaris & 18.95 & 53.2 & 0 & 0 & 6.17 & 4.1 \\
Rattus sp. & 3.38 & 9.5 & 7.67 & 38.9 & 16.96 & 13.3 \\
Sus scrofa & 3.11 & 8.7 & 3.65 & 18.5 & 30.09 & 21.6 \\
Unidentified medium & 10.2 & 28.6 & 8.39 & 42.6 & 85.47 & 61 \\
mammal & & & & & & \\
Total & 35.64 & 100 & 19.71 & 100 & 138.69 & 100 \\
\hline
\end{tabular}

ening of marine foraging to include a greater variety of species. The establishment of more numerous residences along the coastline likely also contributes to this taxonomic richness, as foraging ranges were increased. The remains of pigs, dogs, and unidentified medium mammals also occur in coastal residential deposits for the first time in Period II (AD 1520-1650) and increase dramatically in deposits from Period III (AD 1650-1800). As with the presence of marine shell in the field system, the presence of pig and dog in coastal deposits demonstrates the connections of households within the different ecological zones of the ahupua ' $a$, and provides a line of evidence for the development of the leeward Kohala ahupua 'a into integrated socioeconomic units.

\section{DISCUSSION: LEEWARD KOHALA RESIDENCES AND REGIONAL CHRONOLOGIES}

Intensive study of archaeological features in the LKFS (Ladefoged and Graves 2006, 2008; Ladefoged et al. 2003; Mulrooney and Ladefoged 2005; McCoy et al. 2011) has produced a detailed absolute and relative chronology of agricultural alignments, trails, and religious features. This chronology has traced the development of agriculture in leeward Kohala, and formed the primary chronology for the prehistory of human occupation in the region. Trails, feature abutments, and $a h u$ pua ' $a$ boundaries have also been used to model the development and subdivision of individual ahupua ' $a$ as territories (Ladefoged and Graves 2006), and by proxy to model the development of social hierarchies and paleodemography over time (Ladefoged and Graves 2007).

The details of the field system chronology are similar to the results of the residential dating program presented above. As mentioned, Ladefoged and Graves (2008) indicate that cultivation was most likely initiated in the southern portion of the LKFS as early as AD 1290 and certainly by AD 1430, but it may have entailed shifting cultivation during this period, and not been associated with any constructed trails or agricultural alignments. The paved platform of MKI-300, the enclosure of MKI-303, and the U-shape shelter of KHL-10 are all very small in size $\left(<15 \mathrm{~m}^{2}\right.$ of interior area), and are not abutted by any agricultural alignments. These qualities, coupled with the lack of marine faunal material, indicates that these deposits resulted from activities associated with an early phase of 
settlement in the LKFS (both the southern and central portions), about AD 1400-1520. The deposits associated with features PHH-30 and MKE-106 are their coastal counterparts, and indicate a similar phase of early and probably pioneering settlement on the coast during this period.

The coastal heiau KAL-1 and PHH-13 also yielded ${ }^{14} \mathrm{C}$ samples from beneath their basal stones that date to AD 1400-1630, and surface coral from KAL-1 suggests a maximum age of AD $1603 \pm 12$ for the placement of the coral on the heiau. Heiau were constructed by local Hawaiian communities at boundaries and centers of narrow ahupua ' $a$ to serve as places for tribute collection, which was annually collected from each ahириа ' $a$ during the Makahiki ritual (Malo 1951:144). These dates suggest that the heiau and their tribute collection activities were established sometime after AD 1400, and may indicate that the boundaries between the ahupua ' $a$ of Kālala and Makiloa, and Pahinahina and Kahua-1 were also established after this time. Ladefoged and Graves' analysis of ${ }^{14} \mathrm{C}$ dates from the LKFS suggested that the boundary between the larger combined land unit consisting of Makiloa, Kālala, and adjacent northern ahupua ' $a$, and the larger combined land unit consisting of Pahinahina, Kahua-1, and Kahua-2, predates AD 1420-1667 (Ladefoged and Graves 2008:783). KAL-1 marks the boundary between Kālala and Makiloa, and was probably constructed when Makiloa was subdivided from the larger land unit. PHH-13 marks the southern coastal point of the narrow ahupua ' $a$ of Pahinahina, and was probably constructed when Pahinahina was subdivided from the larger Pahinahina, Kahua-1, and Kahua-2 land unit.

Ladefoged and Graves (2008:784) indicate that the first construction of agricultural features in the form of alignments and trails "probably occurred sometime within the range of AD 1410 to 1630." These alignments (termed phase 1) demarcate major portions of the field system, and divide the ahириа ' $a$ within it into a series of large plots bounded by trails (2008:779). After AD 1660 in the southern ahupua ' $a$, 4 sequential phases of construction occurred, which divided the earlier plots into smaller units. Ladefoged and Graves (2008:784) argue that the establishment of fixed-plot gardens was part of landesque capital improvements, which also divided the landscape into primary territories that were managed by local administrators. The later subdivision of fields occurred when farmers attempted to further demarcate territories, which was perhaps encouraged by the demands of the аһириа ' $a$ chiefs for tribute and surplus food to support their households (Ladefoged and Graves 2008:784). The chronology of residences from Kaiholena and Makeanehu (Field et al. 2011) that abut agricultural alignments and trails similarly tracks the establishment of major (ahupua 'a) and minor ( 'ili) land units, and their subsequent subdivision after AD 1650. Dates from deposits associated with coastal residences in Makeanehu, Kālala, and Makiloa demonstrate an increase in the number of residences during this period, which matches the trajectory of growth established in the field system.

\section{CONCLUSIONS}

The archaeological investigation of residential features in leeward Kohala, Hawai'i Island, allows for a critical evaluation of the chronology of settlement in the region, as well as the size, distribution, and economy of the prehistoric population over the last $600 \mathrm{yr}$. These data are an essential addition to the prehistoric sequence that has been constructed for the Kohala district, which has previously been based primarily upon absolute and relative dating of agricultural features within the LKFS. Our study of residential features utilized excavation, artifact analysis, and absolute dating to document an early phase of settlement in leeward Kohala about AD 1400-1520. The increase in residences over time traces household fission and the demographic growth of the population, which occurred synchronously along the coast and in the interior, and which also corresponds temporally and spatially to the establishment of major portions of the LKFS. Faunal remains of mollusks, echinoderms, 
and domestic dog and pig from residential features reveals the relative focus of subsistence activities throughout prehistory, and indicates that the transport or exchange of foodstuff between the coast and field system emerged later as subsistence expanded beyond the local household. The restriction of large residences with robust wall construction to the final temporal period (AD 1650-1800), and also the expansion of residence size and number similarly reflects a transition from localized household economies to ahupua ' $a$-wide socioeconomic systems that provided surplus and labor to resident chiefs and administrators.

\section{ACKNOWLEDGMENTS}

Survey and excavations in Kohala were funded by National Science Foundation Human Social Dynamics program grant BCS-0624238. Additional financial support was provided by the Class of 1954 Fund of the University of California, Berkeley, the University of Auckland, and the Royal Society of New Zealand Marsden Fund. We thank the State of Hawai'i Department of Land and Natural Resources, the State Historic Preservation Office, Parker Ranch, and Ponoholo Ranch for permission to carry out archaeological research on state and private lands. We also wish to acknowledge and thank Marjeta Jeraj for the identification of the charcoal remains, and Kathy Kawelu, Jenny Kahn, Kris Hara, Jillian Swift, Natalie Shuster, Robin Connors, and Michael Vitousek for their assistance with the excavations. Michael Graves, Mark McCoy, and the students from the Hawai'i Archaeological Research Program (HARP) also provided valuable help with fieldwork. Lastly, the advice and commentary of 2 reviewers was of great benefit to our analyses and writing.

\section{REFERENCES}

Barton CM, Bernabeu J, Aura JE, Garcia O, Schmich S, Molina L. 2004. Long term socioecology and contingent landscapes. Journal of Archaeological Method and Theory 11(3):253-95.

Bonk WJ. 1968. An archaeological survey of a coastal tract in North and South Kohala, Hawai'i [report]. Hilo: Division of State Parks, Department of Lands and Natural Resources.

Bronk Ramsey C. 2001. Development of the radiocarbon calibration program. Radiocarbon 43(2A):355-62.

Bronk Ramsey C. 2009. Bayesian analysis of radiocarbon dates. Radiocarbon 51(1):337-60.

Burgett BD, Rosendahl P. 1993. Summary of archaeological inventory surveys Kapaanui agricultural subdivision and Mahukona property. Lands of Kapaanui, Kou, Kamano, Mahukona 1st and 2nd, Hihiu, and Kaoma. North Kohala District, Island of Hawai ${ }^{\circ} i$ (TMK: 3-5-7-02:11 and TMK: 3-5-7-03:1-3, 10-14, 16-18) [report]. Hilo: Paul H Rosendahl PhD, Inc.

Cheng HR, Edwards L, Hoff J, Gallup CD, Richards DA, Asmerom Y. 2000. The half-lives of uranium-234 and thorium-230. Chemical Geology 169(1-2):17-33.

Dunn AE, Rosendahl P. 1989. Archaeological inventory survey. Kapaanui agricultural subdivision. lands of Kapaanui and Kou. North Kohala District, Island of Hawai'i [report]. Hilo: Paul H Rosendahl PhD, Inc.

Dye TS. 2011. Traditional Hawaiian surface architecture. In: Dye TS, editor. Research Designs for Hawaiian Archaeology. Honolulu: Society for Hawaiian Archaeology. p 93-155.
Ellis W. 1825. A Narrative of an 1823 Tour Through Hawai ' $i$. With remarks on the history, traditions, manners, customs and language of the inhabitants of the Sandwich Islands. New York: Boston, Crocker and Brewster. $484 \mathrm{p}$.

Field JS, Kawelu K, Kirch PV, Ladefoged TN, Connors R. 2008. Archaeological survey and excavations of Makiloa and Kalala Ahupua'a, Kohala, Hawai'i Island, 2007 [report]. Prepared for the State of Hawai ${ }^{\circ}$, the State Historic Preservation Division, and the National Science Foundation.

Field JS, Kirch PV, Ladefoged TN, Connors R, Oxley M. 2009. Archaeological survey and excavations of Pahinahina, Kalala, Kaiholena, and Makeanehu Ahupua'a, Kohala, Hawai'i Island, 2008 [report]. Prepared for the State of Hawai $i$, the State Historic Preservation Division, Parker Ranch LCC, and the National Science Foundation.

Field JS, Kahn J, Kirch PV, Ladefoged TN. 2010a. Archaeological survey and excavations of Pahinahina, Kalala, Makiloa, and Kaiho'oa Ahupua'a, Kohala, Hawai'i Island, 2009 [report]. Prepared for the State Historic Preservation Division, the National Science Foundation, and Ponoholo Ranch LLC.

Field JS, Kirch PV, Kawelu K, Ladefoged TN. 2010 b. Households and hierarchy: domestic modes of production in leeward Kohala, Hawai' i Island. Journal of Island and Coastal Archaeology 5(1):52-85.

Field JS, Ladefoged TN, Kirch PV. 2011. Household expansion linked to agricultural intensification during 
rise of Hawaiian archaic state. Proceedings of the $\mathrm{Na}$ tional Academy of Sciences of the United States of America 108(18):7327-32.

Graves DK, Franklin LJ. 1998. Archaeological inventory survey. Kahua Makai/Kahua shores coastal parcels. Lands of Kahua 1 and 2 and Waika. North Kohala District, Island of Hawai' i (TMK: 3-5-9-01:7, 8) [report]. Hilo: Paul H Rosendahl PhD, Inc.

Graves MW, Ladefoged TN. 1994. The disparity between radiocarbon and volcanic glass dates: new evidence from the island of Lanaii, Hawai' 1 i. Archaeology in Oceania 26(2):70-7.

Green R. 1969. Makaha valley historical project: interim report 1. Pacific Anthropological Records 4. Honolulu: BP Bishop Museum.

Green R. 1970. Makaha valley historical project: interim report 2. Pacific Anthropological Records 10. Honolulu: BP Bishop Museum.

Kaschko M. 1982. Intensive archaeological survey and test excavations. Puakea Bay ranch roadway corridor lands of Honoipu and Puakea, North Kohala, Island of Hawai'`i (TMK: 3-5-6-01:24, 43, 68) [report]. Hilo: Paul H Rosendahl PhD, Inc.

Kirch PV, editor. 2011. Roots of Conflict: Soils, Agriculture, and Sociopolitical Complexity in Ancient Hawai 'i. Santa Fe: School of Advanced Research Press.

Kirch PV, Sharp WD. 2005. Coral ${ }^{230}$ Th dating of the imposition of a ritual control hierarchy in precontact $\mathrm{Ha}$ waii. Science 307(5706):102-4.

Ladefoged TN, Graves MW. 2000. Evolutionary theory and the historical development of dry land agriculture in North Kohala, Hawai'i. American Antiquity 65(3): 423-48.

Ladefoged TN, Graves MW. 2006. The formation of Hawaiian territories. In: Lilley I, editor. Archaeology of Oceania: Australia and the Pacific Islands. Malden: Blackwell Publishers. p 259-83.

Ladefoged TN, Graves MW. 2007. Modeling agricultural development and demography in Kohala, Hawai 'i. In: Kirch PV, Rallu J-L, editors. The Growth, Regulation, and Collapse of Island Societies. Honolulu: University of Hawaii Press. p 70-89.

Ladefoged TN, Graves MW. 2008. Variable development of dryland agriculture in Hawai' $i$ : a fine-grained chronology from the Kohala Field System, Hawai' $i$ Island. Current Anthropology 49(5):771-802.

Ladefoged TN, Graves MW, Coil J. 2005. The introduction of sweet potato in Polynesia: early remains in $\mathrm{Ha}-$ wai' $i$. Journal of the Polynesian Society 114(4):35973.

Ladefoged TN, Graves MW, Jennings RP. 1996. Dryland agricultural expansion and intensification in Kohala, Hawai'i Island. Antiquity 70(270):861-80.

Ladefoged TN, Graves MW, McCoy MD. 2003. Archaeological evidence for agricultural development in Kohala, Island of Hawai'i. Journal of Archaeological Science 30(7):923-40.
Ladefoged TN, Lee C, Graves MW. 2008. Modeling life expectancy and surplus production of dynamic precontact territories in leeward Kohala, Hawai'i. Journal of Anthropological Archaeology 27(1):93-110.

Lee CS, Tuljapurkar S, Vitousek P. 2006. Risky business: temporal and spatial variation in preindustrial dryland agriculture. Human Ecology 34:739-63.

Malo D. 1951. Hawaiian Antiquities. Revised edition [translated by N B Emerson]. Bernice P Bishop Museum Special Publications 2. Honolulu: BP Bishop Museum Press.

McCoy MD, Ladefoged TN, Graves MW, Stephen JW. 2011. Strategies for constructing religious authority in ancient Hawai'i. Antiquity 85(329):927-41.

McGlade J. 1995. Archaeology and the eco-dynamics of human modified landscapes. Antiquity 69(262):11332.

Mulrooney M, Ladefoged TN. 2005. Hawaiian heiau and agricultural production in the Kohala dryland field system. Journal of the Polynesian Society 114:45-65.

Newman TS. 1969. Cultural adaptations to the island of Hawai'i ecosystem: the archaeology on the island of Hawai'i. In: Pearson R, editor. Archaeology on the Island of Hawai' $i$. Asian and Pacific Archaeology Series Volume 3. Honolulu: Social Science Research Insititute. p 3-14.

Newman TS. 1970. Hawaiian Fishing and Farming on the Island of Hawai ' $i$ in AD 1778. Honolulu: Division of State Parks, Department of Lands and Natural Resources.

O'Connor BV. 1998. Spatial and temporal variation in Hawaiian residential architecture: a seriation study of selected coastal settlements in northern Hawai' $i$ Island [MA thesis]. Auckland: University of Auckland.

O'Hare CR, Goodfellow ST. 1995. Archaeological mitigation program data recovery excavations, site 50-1005-4015, Kahua Makai/Kahua shores coastal parcels [report]. Hilo: Paul H Rosendahl PhD, Inc.

Pearson RJ, editor. 1968. Excavations at Lapakahi, N. Kohala, Hawai 'i Island - 1968. Honolulu: Division of State Parks, Department of Land and Natural Resources, Honolulu.

Reimer P, Baillie M, Bard E, Bayliss A, Beck J, Blackwell P, Bronk Ramsey C, Buck C, Burr G, Edwards R, Friedrich M, Grootes P, Guilderson T, Hajdas I, Heaton T, Hogg A, Hughen K, Kaiser K, Kromer B, McCormac FG, Manning S, Reimer R, Richards D, Southon J, Talamo S, Turney C, Van der Plicht J, Weyhenmeyer C. 2009. IntCal09 and Marine09 radiocarbon age calibration curves, $0-50,000$ years cal BP. $R a-$ diocarbon 51(4):1111-50.

Rosendahl P. 1972. Aboriginal agriculture and residence patterns in upland Lapakhi, island of Hawai' ${ }^{\circ}[\mathrm{PhD}$ dissertation]. Honolulu: University of Hawai ${ }^{i}$, Mānoa.

Rosendahl P. 1994. Aboriginal Hawaiian structural remains and settlement patterns in the upland agricul- 
tural zone at Lapakahi, Island of Hawai'i. Hawaiian Archaeology 3:14-70.

Schilt R, Sinoto A. 1980. Limited phase 1 archaeological survey of Mahukona properties, north Kohala, island of Hawai' i [report]. Honolulu: Department of Anthropology, BP Bishop Museum.

Sharp WD, Kahn JG, Polito CM, Kirch PV. 2010. Rapid evolution of ritual architecture in central Polynesia indicated by precise ${ }^{230} \mathrm{Th} / \mathrm{U}$ coral dating. Proceedings of the National Academy of Sciences of the United States of America 107(30):13,234-9.

Soehren LJ. 1969. An archaeological reconnaissance of Parker Ranch coastal lands, north Kohala. In: Pearson $\mathrm{R}$, editor. Archaeology on the Island of Hawai ' $i$. Asian and Pacific Archaeology Series, Volume 3. Honolulu: Social Science Research Institute. p 15-26.
Tuggle HD, Griffin JB. 1973. Lapakahi, Hawai $i$ : Archaeological Studies. Asian and Pacific Archaeology Series, Volume 5. Honolulu: Social Sciences Research Institute.

Tuggle HD, Spriggs M. 2000. The age of the Bellows Dune Site O18, Oahu, Hawai' $i$, and the antiquity of Hawaiian colonization. Asian Perspectives 39(1-2): 165-88.

Vitousek PM, Ladefoged TN, Kirch PV, Hartshorn AS, Graves MW, Hotchkiss SC, Tuljapurkar S, Chadwick OA. 2004. Soils, agriculture, and society in precontact Hawai'i. Science 304(5677):1665-9.

Wulzen W, Goodfellow ST. 1995. Final report. Phased archaeological inventory survey. Phase II - data collection. Chalon International. Mahukona Mauka Parcel [report]. Hilo: Paul H Rosendahl PhD, Inc. 